\title{
COVID-19, Ambient Air Pollution, and Environmental Health Inequities in Latin American Cities
}

\author{
Josiah L. Kephart $\mathbb{D}$ - Ione Avila-Palencia • \\ Usama Bilal • Nelson Gouveia • Waleska T. Caiaffa • \\ Ana V. Diez Roux
}

Accepted: 16 December 2020 / Published online: 20 January 2021

(C) The New York Academy of Medicine 2021

\section{Commentary}

SARS-CoV-2 infections continue to grow in Latin America, where $80 \%$ of the population lives in urban areas that are also home to some of the largest societal inequities in the world. Some national governments across the region have enacted stay-at-home orders, closing schools, and shutting down much of the economy.

High levels of air pollution in many Latin American cities in the past may have primed many residents for more severe infection and mortality from COVID-19 by contributing to the development of chronic diseases. Many of the chronic diseases associated with long-term, cumulative exposure to air pollution appear to be correlated with a higher vulnerability to severe COVID-19 outcomes, including hospitalization, need for critical

J. L. Kephart $(\bowtie) \cdot$ I. Avila-Palencia • U. Bilal •

A. V. Diez Roux

Urban Health Collaborative, Drexel Dornsife School of Public

Health, 3600 Market Street, Philadelphia, PA 19104, USA

e-mail: jlk465@drexel.edu

U. Bilal · A. V. Diez Roux

Department of Epidemiology and Biostatistics, Drexel Dornsife

School of Public Health, Philadelphia, PA, USA

N. Gouveia

Department of Preventive Medicine, University of São Paulo

Medical School, Sao Paulo, Brazil

W. T. Caiaffa

Observatório de Saúde Urbana de Belo Horizonte, Universidade Federal de Minas Gerais, Belo Horizonte, Brazil

care, and death $[1,2]$. A recent study in the USA reported that a long-term increase of only $1 \mu \mathrm{g} / \mathrm{m}^{3}$ $\mathrm{PM}_{2.5}$ was associated with an $8 \%$ increase in COVID19 death rate [3]. In addition to cumulative exposures, it is plausible that short-term air pollution exposures interact with SARS-CoV-2 infection itself [4], possibly via their effects on inflammation-related processes. However, the effect of immediate changes in air pollution on COVID-19-related mortality is yet to be tested.

Even as air pollution may impact COVID-19 outcomes, stay-at-home orders related to COVID-19 have impacted ambient air pollution levels in some Latin American cities [5-7]. We aimed to characterize COVID-19-related reductions in ambient $\mathrm{PM}_{2.5}$ in four major cities in Latin America and to estimate the magnitude of reductions in adult mortality if long-term exposure to $\mathrm{PM}_{2.5}$ was lower proportional to levels observed during the COVID-19 shutdowns. We compared ambient fine particulate matter $\left(\mathrm{PM}_{2.5}\right)$ concentrations during the first week of COVID-19-related school closures in each city with average concentrations for the same period in 2017-2019, using direct measurements from publicly available government air monitor networks in four major Latin American cities. We averaged hourly data from each monitor into a monitor-specific daily mean and considered monitor-days with $<16$ valid hourly means to be missing. Daily means from all monitors within the urban core area were averaged into a citywide daily mean. For each of these four cities, we projected the reduction in all-cause mortality among adults aged $\geq 30$ years if annual ambient $\mathrm{PM}_{2.5}$ concentrations were lower proportional to current COVID-19- 
related reductions (Table 1). We used a well-validated modeled estimate of annual $\mathrm{PM}_{2.5}$ in 2016 [8] as the baseline concentration for each city, to leverage the complete geographic coverage within each city for estimates of city-level exposures. We gathered mortality and population estimates from national governments according to previously described methods [9]. We then applied standard health risk assessment methods from the World Health Organization [10], assuming longterm $\mathrm{PM}_{2.5}$ exposure, a log-linear exposure-response relationship, and an excess risk of all-cause mortality per $10 \mu \mathrm{g} / \mathrm{m}^{3}$ increased $\mathrm{PM}_{2.5}$ exposure of $6 \%(95 \% \mathrm{CI}$ $4 \%, 8 \%)$ [11].

In Lima, weekly mean $\mathrm{PM}_{2.5}$ concentrations were $41 \%$ lower during the first week of COVID-19-related school closures in 2020 than in the same period during the prior 3 years (17 vs. $29 \mu \mathrm{g} / \mathrm{m}^{3}$ ) (Fig. 1). Similarly, weekly $\mathrm{PM}_{2.5}$ concentrations were $31 \%$ lower in São Paulo (9 vs. $13 \mu \mathrm{g} / \mathrm{m}^{3}$ ) and 21\% lower in Santiago (15 vs. $19 \mu \mathrm{g} / \mathrm{m}^{3}$ ). In Mexico City, the difference between 2020 and 2017-2019 was minimal (5\% lower, 21 vs $\left.22 \mu \mathrm{g} / \mathrm{m}^{3}\right)$. We estimate that in a counterfactual scenario of reduced annual $\mathrm{PM}_{2.5}$ proportional to COVID-19related reductions, all-cause mortality among adults aged $\geq 30$ years in Lima would be $7 \%$ lower $(95 \%$ confidence interval [CI] $4 \%$ to $9 \%$ ) with 2522 fewer premature deaths annually (95\% CI 1666 to 3304). In São Paulo, these reductions would result in $3 \%$ lower all-cause mortality (95\% CI 2\% to 4\%) with 3573 fewer premature deaths per year (95\% CI 2341 to 4712 ). Santiago would experience $3 \%$ lower all-cause mortality ( $95 \%$ CI $2 \%$ to $4 \%$ ) with 930 fewer premature deaths annually (95\% CI 610 to 1228). In Mexico City, where observed COVID-19-related ambient $\mathrm{PM}_{2.5}$ reductions were minimal, all-cause mortality would be $0.6 \%$ lower (95\% CI $0.4 \%$ to $0.8 \%$ ) with 730 fewer premature deaths per year (95\% CI 476 to 966 ).
Recent reductions in ambient air pollution in Latin American cities are undoubtedly beneficial and may have significant short-term effects on non-COVID-19 mortality, though the impact of stay-at-home orders on mortality is complex. However, long-term cumulative exposure to ambient air pollution remains a substantial contributor to morbidity and mortality in these urban areas. Within cities in Latin America, chronic conditions and mortality are often distributed along inequitable societal lines [9], with the poor bearing the brunt of the disease burden. Similarly, risk of exposure to SARS-CoV-2 may be higher in lower-income populations through higher rates of residential overcrowding and overrepresentation in occupations with high levels of interaction with the public. Air pollution exposures are also frequently socially patterned and may contribute to higher rates of severe and fatal COVID-19 in lower-income populations, both by influencing the prevalence of chronic conditions and by interacting with SARS-CoV-2 infection directly. If these patterns were confirmed, cities with high air pollution may need to prepare for more intense outbreaks of COVID-19 in poorer neighborhoods and areas with worse air pollution.

A silver lining in the COVID-19 pandemic has been the reductions in air pollution that have followed lockdowns. Within Latin America, policies which reduce air pollution have faced resistance due to perceived economic cost, yet in recent months, we have seen how immediate public health threats can take a firm priority over national economies in ways that seemed impossible just a year ago. Reductions in air pollution during COVID-19 lockdowns are the indirect results of policies not intended to reduce air pollution, and targeted pollution mitigation policies could reduce ambient air pollution at a fraction of the economic cost.

The current reductions in air pollution during COVID-19 lockdown in Latin American cities are

Table 1 Inputs to the analysis of the impact of long-term $\mathrm{PM}_{2.5}$ reductions on all-cause mortality among adults aged 30+ years in four Latin American cities

\begin{tabular}{llllll}
\hline City & Baseline annual $\mathrm{PM}_{2.5} \mu \mathrm{g} / \mathrm{m}^{3}$ & $\begin{array}{l}\text { \% reduction in } \mathrm{PM}_{2.5} \\
\text { during initial COVID-19 } \\
\text { lockdown }\end{array}$ & $\begin{array}{l}\text { Counterfactual long- } \\
\text { term } \mathrm{PM}_{2.5} \mu \mathrm{g} / \mathrm{m}^{3}\end{array}$ & $\begin{array}{l}\text { Population at risk, } \\
\text { aged 30+ years }\end{array}$ & $\begin{array}{l}\text { Mortality rate per } \\
100 \mathrm{k} \text {, aged 30+ years }\end{array}$ \\
\hline Lima & 30 & 41 & 17.7 & $4,876,101$ & 725 \\
São Paulo & 16 & 31 & 11.0 & $11,336,039$ & 1064 \\
Santiago & 22 & 21 & 17.4 & $3,808,372$ & 891 \\
Mexico City & 19 & 5 & 18.1 & $11,362,609$ & 1071 \\
\hline
\end{tabular}


Fig. 1 Weekly $\mathrm{PM}_{2.5}$ concentrations comparing the first week of COVID-19 school closures with the same period in 2017 to 2019 within four Latin American cities

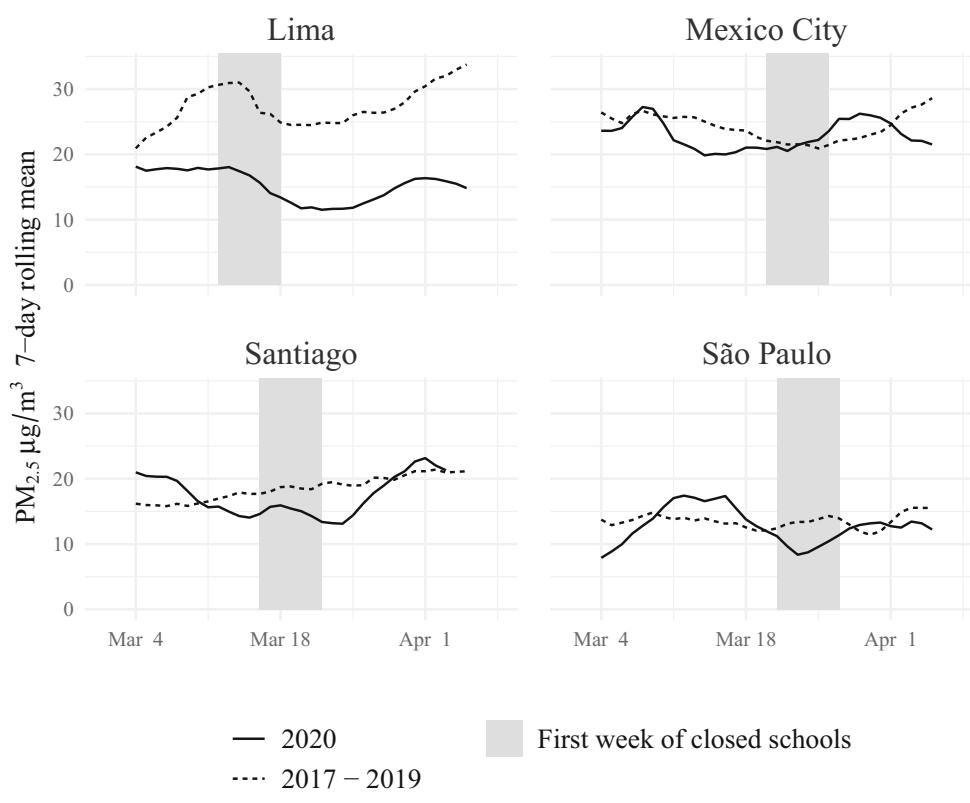

driven by changes across a broad range of emission sources, yet dramatic reductions in vehicular traffic have likely been a major contributor to the air pollution reductions seen during lockdown [7, 12]. Previous interventions to reduce urban air pollution in the region have emphasized policies which reduce vehicular traffic [13-15], yet these interventions have not always been fully evaluated. Reductions in vehicular use during the COVID-19 lockdowns [12] likely far outweigh the reductions achieved by previous interventions [14], yet the transit sector remains a critical sector for costeffective air pollution reductions in the region [16].

As a response to the pandemic, dozens of cities in the region, including Lima [17], Mexico City [18], and Santiago [19] have enacted policies which promote bicycling and walking, often converting car lanes to protected bike or pedestrian lanes [20]. Transitioning to an urban infrastructure which supports biking and walking has enormous potential as an actionable, immediate, and cost-effective intervention to both reduce COVID-19 transmission and air pollution in the short term and support long-term goals of building cities with healthy air that are resistant to future pandemics.

At first glance, it may appear that achieving these reductions absent dramatic lockdowns is unfeasible. Yet, reductions in pollutants comparable or even larger than those observed have occurred in high-income countries as a result of concerted policy efforts and evidence-based regulation. For example, in the USA, annual $\mathrm{PM}_{2.5}$ decreased by $43 \%$ between 2000 and 2018 [21], despite already being at significantly lower levels in 2000 (about $13.5 \mu \mathrm{g} / \mathrm{m}^{3}$ ) than the cities we examine. Although there is growing awareness of the threats of air pollution across the cities of Latin America, levels of many pollutants remain high, and countries have been slow to incorporate WHO guidelines into national-level regulations. Monitoring networks also remain limited [22]. Thus, there is much room for improvement.

Our analysis suggests that even relatively small reductions in ambient air pollution may provide substantial public health benefits. Current levels of ambient air pollution cause 145,000 deaths in Latin America and the Caribbean every year [23], and many more individuals develop chronic respiratory and cardiovascular conditions which severely limit quality of life. As national governments look to reorganize public health systems to become more resilient to pandemics and to restart economies after social distancing measures, there is a critical opportunity to take a fresh look at policies and structural changes which reduce air pollution, prevent chronic diseases, and promote health equity in Latin America and beyond.

Acknowledgments The authors acknowledge the contribution of all SALURBAL project team members. For more information on SALURBAL and to see a full list of investigators, see https://drexel.edu/lac/salurbal/team/. SALURBAL acknowledges the contributions of many different agencies in generating, processing, facilitating access to data or assisting with other 
aspects of the project. Please visit https://drexel.edu/lac/dataevidence for a complete list of data sources. The corresponding author had full access to all the data in the comment and had final responsibility for the decision to submit for publication.

Author Contributions Josiah L. Kephart: conceptualization, writing - original draft, formal analysis. Ione Avila-Palencia: investigation, writing - review and editing. Usama Bilal: conceptualization, supervision, writing - review and editing. Nelson Gouveia: investigation, writing - review \& editing. Waleska T Caiaffa: writing - review and editing. Ana V. Diez Roux: conceptualization, supervision, funding acquisition, writing - review and editing.

Funding The Salud Urbana en América Latina (SALURBAL)/ Urban Health in Latin America project is funded by the Wellcome Trust (205177/Z/16/Z). UB was supported by the Office of the Director of the National Institutes of Health under award number DP5OD26429.

\section{Compliance with Ethical Standards}

Disclaimer The funders had no role in study design, data collection, data analysis, data interpretation, or writing of the report.

\section{References}

1. CDC COVID-19 Response Team. Preliminary estimates of the prevalence of selected underlying health conditions among patients with coronavirus disease 2019 — United States, February 12-March 28, 2020.; 2020. https://doi. org/10.15585/mmwr.mm6913e2.

2. Onder G, Rezza G, Case-Fatality Rate BS. Characteristics of patients dying in relation to COVID-19 in Italy. JAMA - J Am Med Assoc. March 2020; https://doi.org/10.1001 jjama.2020.4683.

3. Wu X, Nethery RC, Sabath BM, Braun D, Dominici F. Exposure to air pollution and COVID-19 mortality in the United States: A nationwide cross-sectional study. medRxiv. 2020:2020.04.05.20054502; https://doi.org/10.1101 /2020.04.05.20054502.

4. Ogen Y. Assessing nitrogen dioxide (NO2) levels as a contributing factor to coronavirus (COVID-19) fatality. Sci Total Environ. 2020;726:138605. https://doi.org/10.1016/j. scitotenv.2020.138605.

5. Dantas G, Siciliano B, França BB, da Silva CM, Arbilla G. The impact of COVID-19 partial lockdown on the air quality of the city of Rio de Janeiro. Brazil. Sci Total Environ. 2020;729:139085. https://doi.org/10.1016/j. scitotenv.2020.139085.

6. Nakada LYK, Urban RC. COVID-19 pandemic: impacts on the air quality during the partial lockdown in São Paulo state. Brazil Sci Total Environ. 2020;730:139087. https://doi. org/10.1016/j.scitotenv.2020.139087.
7. Kutralam-Muniasamy G, Pérez-Guevara F, Roy PD, Elizalde-Martínez I, Shruti VCC. Impacts of the COVID19 lockdown on air quality and its association with human mortality trends in megapolis Mexico City. Air Qual Atmos Heal. October 2020:1-10. https://doi.org/10.1007/s11869020-00960-1.

8. Van Donkelaar A, Martin RV, Brauer M, et al. Global estimates of fine particulate matter using a combined geophysical-statistical method with information from satellites, models, and monitors. Environ Sci Technol. 2016;50(7):3762-72. https://doi.org/10.1021/acs.est.5 b05833.

9. Bilal U, Alazraqui M, Caiaffa WT, et al. Inequalities in life expectancy in six large Latin American cities from the SALURBAL study: an ecological analysis. Lancet Planet Heal. 2019;3(12):e503-10. https://doi.org/10.1016/S25425196(19)30235-9.

10. WHO Regional Office for Europe European Centre for Environment and Health. AirQ+: software tool for health risk assessment of air pollution. 2019. http://www.euro.who. int/en/health-topics/environment-and-health/airquality/activities/airq-software-tool-for-health-riskassessment-of-air-pollution. Accessed 12 April 2020.

11. Hoek G, Krishnan RM, Beelen R, et al. Long-term air pollution exposure and cardio-respiratory mortality: a review. Environ Heal A Glob Access Sci Source. 2013;12(1): 43. https://doi.org/10.1186/1476-069X-12-43.

12. Inter-American Development Bank. Coronavirus Impact Dashboard. https://www.iadb.org/en/topics-effectivenessimproving-lives/coronavirus-impact-dashboard. Published 2020. Accessed November 19, 2020.

13. Carrillo PE, Malik AS, Yoo Y. Driving restrictions that work? Quito's Pico y Placa program. Can J Econ Can d'économique. 2016;49(4):1536-68. https://doi. org/10.1111/caje. 12243 .

14. Davis LWW. The effect of driving restrictions on air quality in Mexico City. J Polit Econ. 2008;116(1):38-81. https://doi.org/10.1086/529398.

15. Martins LC, Latorre M do RD de O, Saldiva PPHN, Braga ALF. Relação entre poluição atmosférica e atendimentos por infecção de vias aéreas superiores no município de São Paulo: avaliação do rodízio de veículos. Rev Bras Epidemiol. 2001;4(3):220-9. https://doi.org/10.1590 /s1415-790x2001000300008.

16. Sefair JA, Espinosa M, Behrentz E, Medaglia AL. Optimization model for urban air quality policy design: a case study in Latin America. Comput Environ Urban Syst. 2019;78:101385. https://doi.org/10.1016/j.compenvurbsys.2019.101385.

17. León JP. Pedalear contra la pandemia. El Comercio. https://especiales.elcomercio.pe/?q=especiales/pedalearcontra-la-pandemia-ecpm/index.html. Published 2020.

18. Ordaz Díaz A. CDMX apuesta por el uso de la bicicleta en la nueva normalidad. Forbes México. https://www.forbes.com. $\mathrm{mx} /$ noticias-cdmx-uso-bicicleta-nueva-normalidad/. Published June 3, 2020. Accessed November 19, 2020.

19. Fernández O, González Lucay C. Mejor en dos ruedas: ante aumento de viajes en bicicleta, comuna de Santiago estrena "ciclosendas." La Tercera. https://www.latercera. com/nacional/noticia/mejor-en-dos-ruedas-ante-aumentode-viajes-en-bicicleta-comuna-de-santiago-estrena- 
ciclosendas/BEI7BGV5KBGNDGTCSZZYDER7JA/. Published June 26, 2020. Accessed November 19, 2020.

20. Combs T, Pardo C, Streetplans, Epiandes, MobilityWorks, Datasketch. The "Shifting Streets" COVID-19 mobility dataset. http://pedbikeinfo.org/resources/resources_details. cfm?id=5235. Published 2020.

21. United States Environmental Protection Agency. Our Nation's Air 2020. https://gispub.epa.gov/air/trendsreport/2020 /\#highlights. Published 2020. Accessed November 25, 2020.

22. Riojas-Rodríguez H, Da Silva AS, Texcalac-Sangrador JL, Moreno-Banda GL. Air pollution management and control in Latin America and the Caribbean: implications for climate change. Rev Panam Salud Publica/Pan Am J Public Heal 2016;40(3):150-159.
23. Stanaway JD, Afshin A, Gakidou E, et al. Global, regional, and national comparative risk assessment of 84 behavioural, environmental and occupational, and metabolic risks or clusters of risks for 195 countries and territories, 19902017: a systematic analysis for the Global Burden of Disease Stu. Lancet. 2018;392(10159):1923-94. https://doi.org/10.1016/S0140-6736(18)32225-6.

Publisher's Note Springer Nature remains neutral with regard to jurisdictional claims in published maps and institutional affiliations. 